Editorial

\section{A trip on the world wide web}

\section{B Pless}

\section{Web based submissions and reviewing are here to stay}

A $\mathrm{s}$ the kids say, moving the journal onto the world wide web has been "a trip". Although if memory serves that phrase is meant to convey something deliriously wonderful (perhaps literally so), this voyage has been like most travels-mainly pleasure but not without its painful moments.

As readers and contributors will all know by now, since May 1 all new manuscripts are handled by our web site (http://submit-ip.bmjjournals.com/) and managed by Bench $>$ Press. For reasons beyond my comprehension this has nearly doubled the rate of new submissions. For an editor, in spite of meaning more work, that is certainly good news ... without papers we starve and die. Much more importantly, however, and far more mysterious is the fact that so many of the new papers are of such high quality. This makes life tough for the editor, but, hey ... why do you think we are so richly rewarded?

The end result is that Injury Prevention now has a longer queue waiting for publication; it needs more pages (some of which the publisher has generously allocated); and it also means that some papers will wait longer before they appear in print. Sadly, it also means that more and more good but not great papers, or great papers that don't quite fit our readership, will get left by the wayside.

In spite of my resolve to be more ruthless in screening out papers that were not likely to be met with much enthusiasm by our reviewers, this influx of good papers has resulted in a larger than expected number going out for review. Most reviewers, old and new, have tolerated the fussy steps required to register with Bench > Press before they can "see" the paper they have been asked to assess. Some, however, have thrown their hands up and said, in effect, "send it by snail mail or drop me from your list". And, dropped they have been, albeit with great reluctance. In fairness, when we were being trained to use Bench $>$ Press, it was predicted that for the most part authors would love the system (once they got past the intimidating conversion to pdf step). It was also predicted that editors would learn to love it-and in any event they had no choice. And, although the trainers did not actually say it, it was evident they assumed that even the dumbest among us would eventually figure out the idiosyncrasies of the system.

With respect to this point, I should add that the backup provided by Bench $>$ Press is magnificent. Marlene Graveland deserves special recognition for her responsiveness and I am personally grateful to her for not making me more ashamed of my shortcomings than I already am, when it comes to using the system properly.

The important prediction was that reviewers were likely to love it the least ... which is a polite way of saying that at best they would tolerate it. That has proven to be an accurate prediction: the benefit of being able to go on line to find which queue your manuscript is languishing in is great for authors but there are no comparable pleasures for reviewers. The best we have to offer is a reasonably quick way to see the comments of fellow reviewers. But this is small consolation for the harassing letters sent by "the system" when it concludes a reviewer is late or has ignored our kind invitation. This sort of behaviour reminds me of the computer Hal in the movie 2001. Scary thought.

Anyway, the future is with us and we must embrace it. Alongside the miracle of web publishing, web based submissions and reviewing are here to stay. I urge our readers to make full use of the journal web site and thank all the contributors who have now been initiated into Bench $>$ Press. But most of all, I thank again, as I do each year as yet another volume draws to a close, all our unsung reviewers. You may safely assume that every member of the editorial board has done at least one review; I hereby formally thank each and every one of them. This year, to conserve space, all other reviewers will be even more unsung than usual. To see a list of all the non-board members who have reviewed one or more papers in the past year, please go to the web site http:// injuryprevention.com/ and follow the links.

My gratitude is endless: reviewers, especially those who are reasonably prompt and reasonably thorough but fair, deserve all the credit for making the whole process work so well. The board, the authors, and above all, the community of injury prevention workers, owe you countless sincere thanks.

Injury Prevention 2002;8:261

\section{Author's affiliation}

I B Pless, Montreal Children's Hospital and McGill University, Montreal, Canada

Correspondence to: Professor Pless; barry.pless@mcgill.ca 